\title{
Prediction of post-progression survival in patients with advanced hepatocellular carcinoma treated with sorafenib by using time-dependent changes in clinical characteristics
}

\author{
Yoshiyuki Wada, Yuko Takami, Hajime Matsushima, Masaki Tateishi, Tomoki Ryu, Munehiro Yoshitomi, \\ Hideki Saitsu
}

Department of Hepato-Biliary-Pancreatic Surgery, Clinical Research Institute, National Hospital Organization Kyushu Medical Center, Fukuoka 810-8563, Japan.

Correspondence to: Dr. Yoshiyuki Wada, Department of Hepato-Biliary-Pancreatic Surgery, Clinical Research Institute, National Hospital Organization Kyushu Medical Center, 1-8-1 Jigyohama, Chuo-ku, Fukuoka 810-8563, Japan. E-mail: yoshiwada@kyumed.jp

How to cite this article: Wada Y, Takami Y, Matsushima H, Tateishi M, Ryu T, Yoshitomi M, Saitsu H. Prediction of post-progression survival in patients with advanced hepatocellular carcinoma treated with sorafenib by using time-dependent changes in clinical characteristics. Hepatoma Res 2018;4:8. http://dx.doi.org/10.20517/2394-5079.2017.39

Received: 1 Sep 2017 First Decision: 20 Sep 2017 Revised: 19 Feb 2018 Accepted: 24 Feb 2018 Published: 6 Mar 2018

Science Editor: Guang-Wen Cao Copy Editor: Jun-Yao Li Production Editor: Huan-Liang Wu

\begin{abstract}
Aim: Sorafenib has been shown to improve time to tumor progression (TTP) and overall survival (OS) in patients with hepatocellular carcinoma (HCC); however, post-progression survival (PPS) has not been well characterized in these patients. This study aimed to evaluate the predictors of PPS by using time-dependent and dynamic changes in radiologic progression patterns, liver function, and performance status (PS) in patients with advanced HCC receiving sorafenib treatment.
\end{abstract}

Methods: We retrospectively analyzed the clinical characteristics of 128 advanced HCC patients with Child-Pugh scores $\mathrm{M} 7$ at the initiation of sorafenib treatment.

Results: The median TTP, OS, and PPS were 3.8, 15.6, and 9.9 months, respectively. At the time of confirmation of radiologic progressive disease (PD), a total of $46(35.6 \%)$ patients showed impairments in their PS of $\geq+1$ points over time. For the Child-Pugh score, $27(21.1 \%)$ and 26 (10.9\%) patients exhibited an impairment of $\geq+1$ and $\geq+2$ points, respectively. Multivariate analysis identified the following independent predictors of PPS: impairment in the PS score of $\geq+1$ point [hazard ratio (HR) 1.81, 95\% confidence interval (CI) 1.16-2.82], impairment in the ChildPugh score of $\geq+2$ points (HR 3.70,95\% $\mathrm{Cl} 1.68-8.15$ ), radiologic pattern of progression (target lesion growth and emergence of a new lesion) (HR 2.91,95\% Cl 1.79-2.91), a TTP < 4 months (HR 1.87, 95\% Cl 1.21-2.91), second-line treatment after radiologic confirmation of PD (HR $0.16,95 \% \mathrm{Cl} 0.08-0.32)$, and continuous sorafenib treatment after radiologic confirmation of PD (HR 1.76, 95\% Cl 1.06-3.00).

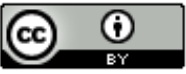

(C) The Author(s) 2018. Open Access This article is licensed under a Creative Commons Attribution 4.0 International License (https://creativecommons.org/licenses/by/4.0/), which permits unrestricted use, sharing, adaptation, distribution and reproduction in any medium or format, for any purpose, even commercially, as long as you give appropriate credit to the original author(s) and the source, provide a link to the Creative Commons license, and indicate if changes were made.

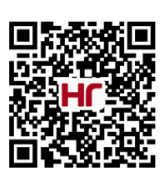


Conclusion: PPS in patients with advanced HCC can be characterized by using time-dependent dynamic changes in clinical parameters.

Keywords: Contactin-associated protein-2, Isaac, neuromuscular hyperexcitability, neuromyotonia, voltage-gated potassium channel

\section{INTRODUCTION}

Hepatocellular carcinoma (HCC) is the third common cause of cancer-related deaths worldwide. Surgical resection, liver transplantation, and ablation therapy are curative therapeutic treatments for early-stage HCC, and transcatheter arterial chemoembolization (TACE) is recommended for patients with intermediate-stage HCC who have preserved liver function ${ }^{[1,2]}$. However, most HCC patients are diagnosed during the advanced stage of the disease; their prognosis is poor, and treatment options are limited ${ }^{[1-3]}$. In patients who are not candidates for locoregional therapy, the oral multikinase inhibitor sorafenib has been the only systemic treatment option. Sorafenib inhibits tumor cell proliferation and tumor angiogenesis by inhibiting multiple signaling pathways. It has been shown to prolong both, progression-free survival and overall survival (OS) in patients with advanced HCC $^{[4,5]}$. Since the Sorafenib HCC Assessment Randomized Protocol (SHARP) trial showed the efficacy of sorafenib for prolonging survival in HCC patients almost 10 years ago ${ }^{[4]}$, all phase 3 trials of novel systemic drugs have failed to improve outcomes over sorafenib, both, as first-line ${ }^{[6-10]}$ and second-line treatments (following sorafenib) ${ }^{[10-12]}$. Predicting the efficacy is difficult in sorafenib treatment, and no surrogate marker has been identified ${ }^{[1-13]}$. Since tumor progression is a dynamic process, it may be difficult to identify predictors for survival by analyzing clinical characteristic at one static data point. Using dynamic data might help clarify the predictors of survival.

A recent regorafenib for patients with HCC who progressed on sorafenib treatment (RESORCE) study ${ }^{[14]}$ has revealed that regorafenib prolonged survival in patients with advanced HCC who were refractory to sorafenib treatment. The inclusion criteria in this study were a Child-Pugh score $\leq 6$ and tolerability of sorafenib ( $\geq 400 \mathrm{mg}$ daily for at least 20 of the 28 days before discontinuation). Based on this, the number of candidates for second-line treatment with regorafenib is likely very limited. Analyzing post-progression survival (PPS) after sorafenib treatment is desired to select candidates for second-line treatment.

In this study, we used dynamic and time-dependent data on the clinical characteristics of patients with advanced HCC, including progression patterns, impairments in liver function, and performance status (PS). Importantly, we assessed changes in these parameters by comparing them at the time of radiologic confirmation of progressive disease (PD) to baseline (the initiation of sorafenib treatment) to evaluate PPS.

\section{METHODS}

\section{Patients}

We reviewed data that were prospectively collected from 171 consecutive patients who received sorafenib (Nexavar; Bayer HealthCare Pharmaceuticals, West Haven, CT, USA) for the treatment of advanced HCC at the Department of Hepato-Biliary-Pancreatic Surgery at the National Hospital Organization Kyushu Medical Center between June 2009 and July 2016. Of these, 135 patients had radiologic PD, as assessed by the modified Response Evaluation Criteria In Solid Tumors (mRECIST) ${ }^{[15]}$. After excluding 7 patients with a Child-Pugh score $\geq 8,128$ patients were enrolled in the study.

HCC was diagnosed based on the results of a pathological examination or a combination of specific radiologic findings obtained via contrast-enhanced computed tomography (CT) or magnetic resonance imaging (MRI) according to the criteria of the American Association for the Study of Liver Diseases ${ }^{[2]}$. 
Of 128 patients, 116 were diagnosed with HCC based on the results of a pathological examination. The remaining 12 patients showed specific radiologic findings according to the criteria of the AASLD and elevated serum $\alpha$-fetoprotein (AFP) levels. No patients with differentiated intracholangiocellular carcinoma and mixed-form liver cancer were included in this study.

Sorafenib was administered to patients with advanced HCC if: (1) they were not eligible for or their disease progressed after surgery, locoregional therapy, or TACE; (2) their ECOG PS was 0-1; (3) their liver function was classified as Child-Pugh A or B; and (4) they had adequate hepatic function (albumin $>2.5 \mathrm{~g} / \mathrm{dL}$, total bilirubin $<3.0 \mathrm{mg} / \mathrm{dL}$, and alanine aminotransferase and aspartate aminotransferase levels $<5$ times the upper limit of the normal range). Radiologic tumor progression was confirmed by contrast-enhanced CT or MRI. The starting dosage of sorafenib was $800 \mathrm{mg} /$ day p.o. However, considering the possibility of having to discontinue sorafenib treatment at an early stage due to adverse events, the initial dosage for patients with comorbidities was reduced to $400 \mathrm{mg} /$ day. Moreover, the initial dosage for patients aged $\geq 75$ years, those with a body weight $\leq 40 \mathrm{~kg}$, and those with a history of treatment for varices or ascites was 200-400 mg/day. The dose was increased to the standard dose according to each patient's tolerance. Treatment was continued until tumor progression, unacceptable toxicity associated with sorafenib, or withdrawal of consent. Second-line treatments after radiologic confirmation of PD included continuous sorafenib treatment, even in palliative patients upon their request. However, patients with Child-Pugh C or a PS $>2$ at the time of confirmation of PD received best supportive care.

This study was approved by the Ethics Committee of the National Hospital Organization Kyushu Medical Center and performed in compliance with the Declaration of Helsinki. All patients provided written informed consent for sorafenib treatment.

\section{Assessments}

Tumor measurements were performed at baseline and every 2 months during treatment by contrastenhanced CT or MRI. Patients visited the clinic every 2 to 4 weeks to assess treatment compliance and adverse effects. The survival status of the study participants was obtained from hospital records. Local response was determined by the mRECIST criteria ${ }^{[15]}$. We assessed the cause of progression (patterns of progression) based on the following: $20 \%$ increase in tumor size against a known baseline lesion or the emergence of a new lesion.

\section{Follow-up}

All patients were followed-up at our outpatient clinic according to a standardized protocol that included tumor marker tests every month and MDCT or MRI every 8 weeks until the patient's death or last visit.

\section{Statistical analysis}

Statistical analyses were conducted using the JMP version 11.0 software (SAS Institute, Cary, NC, USA). Categorical variables were analyzed with the Chi-square or Fisher's exact test, as appropriate. Continuous variables were analyzed using the Student's $t$-test or the Mann-Whitney $U$ test, as appropriate. Time to tumor progression (TTP), OS, and PPS were evaluated through the Kaplan-Meier method, and comparisons between groups were performed using the log-rank test. Univariate and multivariate analyses were performed using a Cox proportional hazards model and the backward elimination procedure. A $P$-value of $<0.05$ was considered significant.

\section{RESULTS}

\section{Baseline characteristics of the patients}

The average age of the 128 study participants (105 men and 23 women) was 68.9 years [Table 1]. Most $(n=100)$ had a PS of 0 . Regarding the preservation of liver function, 71, 43, and 14 study participants had 
Table 1. Characteristics at the initiation of sorafenib treatment

\begin{tabular}{lll}
\hline Variables & & $\boldsymbol{n = 1 2 8}$ \\
\hline Age, year & & 68.9 \\
Gender & (male/female) & $105 / 23$ \\
Etiology & HBV/HCV/NBNC & $21 / 86 / 21$ \\
ECOG PS & $0 / 1$ & $100 / 28$ \\
Child-Pugh score & $5 / 6 / 7$ & $71 / 43 / 14$ \\
Extrahepatic spread & & $65(51.2 \%)$ \\
Macrovascular invasion & & $29(23.6 \%)$ \\
BCLC stage & B/C & $34 / 94$ \\
Starting dose of sorafenib & $800 / 600 / 400 / 200$ & $26 / 0 / 83 / 16$ \\
AFP $(\mathrm{ng} / \mathrm{mL})$ & (median, IQR) & $55.3(8.4-469)$ \\
DCP $(\mathrm{mAu} / \mathrm{mL})$ & (median, IQR) & $92.5(22-1877)$ \\
\hline
\end{tabular}

HBV: hepatitis B virus; HCV: hepatitis C virus; NBNC: non B non C; ECOG: Eastern Cooperative Oncology Group; PS: performance status; BCLC: Barcelona Clinical Liver Cancer; AFP: a-fetoprotein; DCP: des-g-carboxy prothrombin; IQR: interquartile range

Table 2. Change of clinical parameters at the time of confirmation of radiologic progressive disease compared with those of the initiation of sorafenib treatment

\begin{tabular}{llc}
\hline Variables & & At the confirmation of radiologic PD \\
\hline Impairment of PS score & $\geq+1$ & $46(35.9 \%)$ \\
& $\geq+2$ & $14(10.9 \%)$ \\
Impairment of Child-Pugh score & $\geq+1$ & $27(21.1 \%)$ \\
& $\geq+2$ & $26(20.3 \%)$ \\
Time to progression & $\geq 4$ months & $60(46.9 \%)$ \\
Radiologic progression pattern & Target lesion growth & $63(49.2 \%)$ \\
& New lesion & $19(14.8 \%)$ \\
& Target lesion growth and new lesion & $46(35.9 \%)$ \\
\hline
\end{tabular}

PD: progressive disease; PS: performance status

a Child-Pugh score of 5, 6, and 7, respectively. Whereas 65 patients presented with extrahepatic spread, 29 showed macrovascular invasion. At total of 34 and 94 study participants had Barcelona Clinical Liver Cancer (BCLC) stages B and C, respectively.

\section{Second-line treatment after radiologic confirmation of PD}

At the time of the radiologic confirmation of PD, 96 (75.0\%) patients received subsequent second-line treatment. Of 96 patients who underwent subsequent treatment, 59 received continuous sorafenib treatment, 17 underwent TACE, 8 took part in clinical trials, 5 received hepatic arterial infusion chemotherapy, 5 underwent systemic chemotherapy, and 2 received radiotherapy.

\section{TTP, OS, and PPS}

The median TTP and OS were 3.8 months [95\% confidence interval (CI), 3.2-4.4] and 15.6 months (95\% CI, 12.4-18.5), respectively. The median PPS was 9.9 months (95\% CI, 7.6-12.9). The TTP in this study was similar to those reported in the SHARP and AP trials.

\section{Changes in clinical characteristics between baseline (the initiation of sorafenib treatment) and confirmation of radiologic PD}

We then assessed the dynamic changes in the patients' clinical characteristics and compared them at baseline (the initiation of sorafenib treatment) to the confirmation of radiologic PD [Table 2]. A total of 46 (35.6\%) and $14(10.9 \%)$ patients showed impairments in their PS of $\geq+1$ and $\geq+2$ points over time, respectively. For the Child-Pugh score, 27 (21.1\%) and 26 (20.3\%) patients exhibited an impairment of $\geq+1$ and $\geq+2$ points, respectively. When we assessed the radiologic patterns of progression, 63, 19, and 46 patients showed target lesion growth only, emergence of a new lesion only, and both, target lesion growth and emergence of a new 
Table 3. Predictive factors for post-progression survival

\begin{tabular}{|c|c|c|c|c|c|}
\hline \multirow[b]{2}{*}{ Variables } & & \multicolumn{2}{|c|}{ Univariate } & \multicolumn{2}{|c|}{ Multivariate } \\
\hline & & HR (95\% CI) & $P$ value & HR $(95 \% \mathrm{Cl})$ & $P$ value \\
\hline Age, year & $\geq 75$ & $1.11(0.72-1.66)$ & 0.64 & & \\
\hline Gender & Male & $1.07(0.67-1.79)$ & 0.79 & & \\
\hline Hepatitis B infection & Yes & $0.95(0.56-1.53)$ & 0.84 & & \\
\hline Hepatitis C infection & Yes & $0.87(0.58-1.32)$ & 0.5 & & \\
\hline \multirow[t]{2}{*}{ Impairment of PS } & $\geq+1$ point & $2.14(1.45-3.17)$ & $<0.001$ & $1.81(1.16-2.82)$ & 0.01 \\
\hline & $\geq+2$ points & $8.54(4.31-16.12)$ & $<0.001$ & $1.12(0.47-2.62)$ & 0.79 \\
\hline \multirow[t]{2}{*}{ Impairment of Child-Pugh score } & $\geq+1$ point & $2.21(1.48-3.28)$ & $<0.001$ & $1.10(0.64-1.99)$ & 0.73 \\
\hline & $\geq+2$ points & $4.82(2.93-7.68)$ & $<0.001$ & $3.70(1.68-8.15)$ & $<0.01$ \\
\hline Extrahepatic spread & Yes & $1.4(0.94-2.08)$ & 0.15 & & \\
\hline Macrovascular invasion & Yes & $2.01(1.25-3.13)$ & 0.03 & $1.08(0.58-1.96)$ & 0.80 \\
\hline BCLC stage & $\mathrm{C}$ & $1.83(1.19-2.90)$ & $<0.01$ & $1.33(0.80-2.23)$ & 0.27 \\
\hline Radiological progression pattern & Growth + new & $3.21(2.09-4.91)$ & $<0.001$ & $2.91(1.79-4.76)$ & $<0.001$ \\
\hline Time to tumor progression & $<4$ months & $2.25(1.52-3.35)$ & $<0.001$ & $1.87(1.21-2.91)$ & 0.01 \\
\hline Second-line treatment post-PD & Yes & $0.12(0.07-0.20)$ & $<0.001$ & $0.16(0.08-0.32)$ & $<0.001$ \\
\hline $\begin{array}{l}\text { Contiunuous sorafenib treatment } \\
\text { post-PD }\end{array}$ & Yes & $0.67(0.45-0.98)$ & 0.04 & $1.76(1.06-3.00)$ & 0.03 \\
\hline $\begin{array}{l}\text { Decline of serum AFP level } 2 \text { weeks } \\
\text { after starting sorafenib }\end{array}$ & $>20 \%$ & $1.19(0.72-1.89)$ & 0.48 & & \\
\hline
\end{tabular}

BCLC: Barcelona Clinical Liver Cancer; AFP: a-fetoprotein; PD: progressive disease; PS: performance status; HR: hazard ratio; CI: confidence interval

lesion, respectively. Of 34 patients with BCLC-B, 4 progressed to BCLC-C at the time of confirmation of radiologic PD based on new extrahepatic spread $(n=3)$ or occurrence of a portal tumor thrombus $(n=1)$.

\section{Prediction of PPS}

Univariate analysis revealed a significant correlation between PPS and the following parameters in patients with radiologic PD: impairments in the PS score of $\geq+1$ and $\geq+2$ points, a Child-Pugh score of 8 , impairments in the Child-Pugh score of $\geq+1$ and $\geq+2$ points, macrovascular invasion, radiologic patterns of progression, a TTP of $\leq 4$ months, subsequent treatment post-PD, and continuous sorafenib treatment post-PD [Table 3]. Multivariate analysis identified the following independent predictors of PPS in patients with radiologic PD: impairment in the PS score of $\geq+1$ point [hazard ratio (HR) 1.81, 95\% CI 1.162.82], impairment in the Child-Pugh score of $\geq+2$ points (HR 3.70, 95\% CI 1.68-8.15), radiologic pattern of progression (target lesion growth and emergence of a new lesion) (HR 2.91, 95\% CI 1.79-2.91), a TTP < 4 months (HR 1.87, 95\% CI 1.21-2.91), second-line treatment after radiologic confirmation of PD (HR 0.16, 95\% CI 0.08-0.32), and continuous sorafenib treatment after radiologic confirmation of PD (HR 1.76, 95\% CI 1.06-3.00) [Table 3].

\section{DISCUSSION}

In our analysis of 128 patients with advanced HCC, we found impairment in the PS score of $\geq+1$, impairment in the Child-Pugh score of $\geq+2$, a TTP $<4$ months, radiologic progression pattern, secondline treatment after radiologic confirmation of $\mathrm{PD}$, and continuous sorafenib treatment after radiologic confirmation of PD were predictors of PPS. Time-dependent changes in these clinical parameters played an important role in predicting PPS.

PPS has been shown to be associated with OS in patients with lung ${ }^{[16]}$, breast ${ }^{[17]}$, and colorectal cancer ${ }^{[18]}$. Recently, a correlation between PPS and OS was also shown in patients with HCC $^{[19,20]}$. However, to the best of our knowledge, few investigations have assessed the role of dynamic and time-dependent changes in clinical characteristics in the prediction of PPS.

Based on the findings of this study, patients with advanced HCC can be referred for second-line treatment at confirmation of PD during sorafenib treatment. Our findings also imply that observing disease progression 
during sorafenib treatment is very important. A decrease in liver function or a worsening in the patients' general condition during sorafenib treatment should be detected early as these patients should be referred for second-line treatment as early as possible.

Our data revealed that an impairment in the Child-Pugh score of $\geq+2$ points (and not $\geq+1$ points) but was associated with a worse PPS. In previous studies, liver function impairment was defined as Child-Pugh score B or C. However, using this definition, an impairment in the Child-Pugh score of +1 point would be only defined as liver function impairment in patients with a Child-Pugh score of A6 at baseline, but not for those with a Child-Pugh score of A5 at baseline. Furthermore, the Child-Pugh score at the confirmation of PD may not accurately represent the development of the condition. In this study, we therefore focused on the changes in Child-Pugh scores over time to evaluate the effect on PPS of a change in the score of +1 point.

PS has been shown to correlate strongly with both, tumor and cirrhotic factors, and may predict survival outcomes in patients with advanced $\mathrm{HCC}^{[21,22]}$. In previous studies, liver function impairment was defined as a PS $>2{ }^{[19,20]}$. In contrast, this study showed that even an impairment in PS of $\geq+1$ point was associated with a worse PPS.

A recent study by Reig et al. ${ }^{[19]}$ showed that the radiologic progression pattern affected both, OS and PPS in HCC patients receiving sorafenib treatment. The radiologic progression pattern in previous studies included intrahepatic growth, new intrahepatic lesion, extrahepatic growth, or new extrahepatic lesion. Patients with a new extrahepatic lesion, in particular, had a worse PPS ${ }^{[19,20]}$. When estimating a tumor response, radiologic examinations show a certain progression pattern in some patients; however, many patients have a complicated combination of progression patterns. Estimated all combination of these progression patterns, complicated combination may be difficult to comprehend. In this study, we adopted the progression pattern of target lesion growth and/or the emergence of a new lesion for a convenient and easily available approach in clinical practice.

Interestingly, a TTP of $<4$ months was identified as an independent prognostic predictor in this study. A recent study reported that a TTP of $<4$ months was an independent predictor of OS and PPS ${ }^{[20]}$. Earlier PD development predicts a poorer PPS after adjusting for other survival predictors. These patients should be referred for second-line treatment. It has been reported that continuous sorafenib treatment was a useful treatment option at the time of radiologic confirmation of PD. Moreover, our previous study showed that continuing sorafenib treatment after radiologic confirmation of PD may be a useful treatment strategy, especially in patients with a TTP of $\geq 4$ months ${ }^{[23]}$. On the other hand, for patients with rapid PD, as defined by a TTP of $<4$ months, alternative second-line treatments should be considered ${ }^{[24]}$.

This study had some limitations. First, this study was a retrospective study. However, all patients underwent tumor evaluation by contrast-enhanced CT or MRI every 2 months during sorafenib treatment. Furthermore, no patient was lost to follow-up. Second, the study only enrolled patients with a Child-Pugh score of $\leq 7$. Clinical trials of sorafenib showed the drug's efficacy in patients with a Child-Pugh score of $\leq 6$. However, global ${ }^{[25]}$ and Japanese ${ }^{[26]}$ observational studies revealed that sorafenib treatment was often initiated in patients with a Child-Pugh score of 7 in clinical practice. Third, the target population of this study was heterogenous and included patients with BCLC-B and -C. However, sorafenib treatment is often used for HCC patients with BCLC-B who are refractory to TACE in clinical practice. Furthermore, predictors of PPS were analyzed after adjusting for BCLC staging. Fourth, 17 patients treated with TACE as a second-line treatment after the confirmation of radiologic PD were included in this study, as it is common practice to use a combination therapy of TACE and sorafenib to control disease progression. However, the efficacy of a combination therapy of TACE and sorafenib is still controversial and should be confirmed in a randomized clinical trial ${ }^{[27]}$. Fifth, radiologic progression pattern, as mentioned before. Finally, the size of the study 
cohort was small. Therefore, further prospective studies with a larger number of subjects are required to confirm our findings.

In conclusion, we show that evaluating PPS in patients with advanced HCC by using time-dependent and dynamic changes in clinical parameters was extremely useful. Our findings may be useful for selecting second-line treatment at the time of PD. Furthermore, our data indicate that changes in liver function or worsening of a patient's general condition during sorafenib treatment should be observed carefully.

\section{DECLARATIONS}

\section{Authors' contributions}

All authors contributed equally to this work.

\section{Data source and availability}

The datasets generated during and/or analysed during the current study are available from the corresponding author on reasonable request.

\section{Financial support and sponsorship}

None.

\section{Conflicts of interest}

The authors declare no conflicts of interest associated with this manuscript.

\section{Patient consent}

All patients provided written informed consent for sorafenib treatment.

\section{Ethics approval}

This study was approved by the Ethics Committee of the National Hospital Organization Kyushu Medical Center and performed in compliance with the Declaration of Helsinki.

\section{Copyright}

(c) The Author(s) 2018.

\section{REFERENCES}

1. European Association for the Study of the Liver; European Organisation for Research and Treatment of Cancer. EASL-EORTC clinical practice guidelines: management of hepatocellular carcinoma. $J$ Hepatol 2012;56:908-43.

2. Bruix J, Sherman M. Management of hepatocellular carcinoma: an update. Hepatology 2011;53:1020-2.

3. Giannini EG, Farinati F, Ciccarese F, Pecorelli A, Rapaccini GL, Di Marco M, Benvegnu L, Caturelli E, Zoli M, Borzio F, Chiaramonte M, Trevisani F. Prognosis of untreated hepatocellular carcinoma. Hepatology 2015;61:184-90.

4. Llovet JM, Ricci S, Mazzaferro V, Hilgard P, Gane E, Blanc JF, de Oliveira AC, Santoro A, Raoul JL, Forner A, Schwartz M, Porta C, Zeuzem S, Bolondi L, Greten TF, Galle PR, Seitz JF, Borbath I, Haussinger D, Giannaris T, Shan M, Moscovici M, Voliotis D, Bruix J. Sorafenib in advanced hepatocellular carcinoma. N Engl J Med 2008;359:378-90.

5. Cheng AL, Kang YK, Chen Z, Tsao CJ, Qin S, Kim JS, Luo R, Feng J, Ye S, Yang TS, Xu J, Sun Y, Liang H, Liu J, Wang J, Tak WY, Pan H, Burock K, Zou J, Voliotis D, Guan Z. Efficacy and safety of sorafenib in patients in the Asia-Pacific region with advanced hepatocellular carcinoma: a phase III randomised, double-blind, placebo-controlled trial. Lancet Oncol 2009;10:25-34.

6. Cheng AL, Kang YK, Lin DY, Park JW, Kudo M, Qin S, Chung HC, Song X, Xu J, Poggi G, Omata M, Pitman Lowenthal S, Lanzalone S, Yang L, Lechuga MJ, Raymond E. Sunitinib versus sorafenib in advanced hepatocellular cancer: results of a randomized phase III trial. J Clin Oncol 2013;31:4067-75.

7. Johnson PJ, Qin S, Park JW, Poon RT, Raoul JL, Philip PA, Hsu CH, Hu TH, Heo J, Xu J, Lu L, Chao Y, Boucher E, Han KH, Paik SW, Robles-Avina J, Kudo M, Yan L, Sobhonslidsuk A, Komov D, Decaens T, Tak WY, Jeng LB, Liu D, Ezzeddine R, Walters I, Cheng AL. Brivanib versus sorafenib as first-line therapy in patients with unresectable, advanced hepatocellular carcinoma: results from the randomized phase III BRISK-FL study. J Clin Oncol 2013;31:3517-24.

8. Cainap C, Qin S, Huang WT, Chung IJ, Pan H, Cheng Y, Kudo M, Kang YK, Chen PJ, Toh HC, Gorbunova V, Eskens FA, Qian J, McKee MD, Ricker JL, Carlson DM, El-Nowiem S. Linifanib versus sorafenib in patients with advanced hepatocellular carcinoma: 
results of a randomized phase III trial. J Clin Oncol 2015;33:172-9.

9. Zhu AX, Rosmorduc O, Evans TR, Ross PJ, Santoro A, Carrilho FJ, Bruix J, Qin S, Thuluvath PJ, Llovet JM, Leberre MA, Jensen M, Meinhardt G, Kang YK. SEARCH: a phase III, randomized, double-blind, placebo-controlled trial of sorafenib plus erlotinib in patients with advanced hepatocellular carcinoma. J Clin Oncol 2015;33:559-66.

10. Llovet JM, Decaens T, Raoul JL, Boucher E, Kudo M, Chang C, Kang YK, Assenat E, Lim HY, Boige V, Mathurin P, Fartoux L, Lin DY, Bruix J, Poon RT, Sherman M, Blanc JF, Finn RS, Tak WY, Chao Y, Ezzeddine R, Liu D, Walters I, Park JW. Brivanib in patients with advanced hepatocellular carcinoma who were intolerant to sorafenib or for whom sorafenib failed: results from the randomized phase III BRISK-PS study. J Clin Oncol 2013;31:3509-16.

11. Zhu AX, Kudo M, Assenat E, Cattan S, Kang YK, Lim HY, Poon RT, Blanc JF, Vogel A, Chen CL, Dorval E, Peck-Radosavljevic M, Santoro A, Daniele B, Furuse J, Jappe A, Perraud K, Anak O, Sellami DB, Chen LT. Effect of everolimus on survival in advanced hepatocellular carcinoma after failure of sorafenib: the EVOLVE-1 randomized clinical trial. JAMA 2014;312:57-67.

12. Zhu AX, Park JO, Ryoo BY, Yen CJ, Poon R, Pastorelli D, Blanc JF, Chung HC, Baron AD, Pfiffer TE, Okusaka T, Kubackova K, Trojan J, Sastre J, Chau I, Chang SC, Abada PB, Yang L, Schwartz JD, Kudo M. Ramucirumab versus placebo as second-line treatment in patients with advanced hepatocellular carcinoma following first-line therapy with sorafenib (REACH): a randomised, double-blind, multicentre, phase 3 trial. Lancet Oncol 2015;16:859-70.

13. Llovet JM, Pena CE, Lathia CD, Shan M, Meinhardt G, Bruix J. Plasma biomarkers as predictors of outcome in patients with advanced hepatocellular carcinoma. Clin Cancer Res 2012;18:2290-300.

14. Bruix J, Qin S, Merle P, Granito A, Huang YH, Bodoky G, Pracht M, Yokosuka O, Rosmorduc O, Breder V, Gerolami R, Masi G, Ross PJ, Song T, Bronowicki JP, Ollivier-Hourmand I, Kudo M, Cheng AL, Llovet JM, Finn RS, LeBerre MA, Baumhauer A, Meinhardt G, Han G. Regorafenib for patients with hepatocellular carcinoma who progressed on sorafenib treatment (RESORCE): a randomised, double-blind, placebo-controlled, phase 3 trial. Lancet 2017;389:56-66.

15. Lencioni R, Llovet JM. Modified RECIST (mRECIST) assessment for hepatocellular carcinoma. Semin Liver Dis 2010;30:52-60.

16. Hotta K, Kiura K, Fujiwara Y, Takigawa N, Hisamoto A, Ichihara E, Tabata M, Tanimoto M. Role of survival post-progression in phase III trials of systemic chemotherapy in advanced non-small-cell lung cancer: a systematic review. PLoS One 2011;6:e26646.

17. Saad ED, Katz A, Buyse M. Overall survival and post-progression survival in advanced breast cancer: a review of recent randomized clinical trials. J Clin Oncol 2010;28:1958-62.

18. Petrelli F, Barni S. Correlation of progression-free and post-progression survival with overall survival in advanced colorectal cancer. Ann Oncol 2013;24:186-92.

19. Reig M, Rimola J, Torres F, Darnell A, Rodriguez-Lope C, Forner A, Llarch N, Rios J, Ayuso C, Bruix J. Postprogression survival of patients with advanced hepatocellular carcinoma: rationale for second-line trial design. Hepatology 2013;58:2023-31.

20. Lee IC, Chen YT, Chao Y, Huo TI, Li CP, Su CW, Lin HC, Lee FY, Huang YH. Determinants of survival after sorafenib failure in patients with BCLC-C hepatocellular carcinoma in real-world practice. Medicine (Baltimore) 2015;94:e688.

21. Hsu CY, Lee YH, Hsia CY, Huang YH, Su CW, Lin HC, Lee RC, Chiou YY, Lee FY, Huo TI. Performance status in patients with hepatocellular carcinoma: determinants, prognostic impact, and ability to improve the Barcelona Clinic Liver Cancer system. Hepatology 2013;57:112-9.

22. Huitzil-Melendez FD, Capanu M, O’Reilly EM, Duffy A, Gansukh B, Saltz LL, Abou-Alfa GK. Advanced hepatocellular carcinoma: which staging systems best predict prognosis? J Clin Oncol 2010;28:2889-95.

23. Wada Y, Takami Y, Tateishi M, Ryu T, Mikagi K, Saitsu H. The efficacy of continued sorafenib treatment after radiologic confirmation of progressive disease in patients with advanced hepatocellular carcinoma. PLoS One 2016;11:e0146456.

24. Nakano M, Tanaka M, Kuromatsu R, Nagamatsu H, Satani M, Niizeki T, Okamura S, Iwamoto H, Shimose S, Shirono T, Noda Y, Koga $\mathrm{H}$, Torimura T. Alternative treatments in advanced hepatocellular carcinoma patients with progressive disease after sorafenib treatment: a prospective multicenter cohort study. Oncotarget 2016;7:64400-9.

25. Marrero JA, Kudo M, Venook AP, Ye SL, Bronowicki JP, Chen XP, Dagher L, Furuse J, Geschwind JH, de Guevara LL, Papandreou C, Takayama T, Sanyal AJ, Yoon SK, Nakajima K, Lehr R, Heldner S, Lencioni R. Observational registry of sorafenib use in clinical practice across child-pugh subgroups: the gideon study. J Hepatol 2016;65:1140-7.

26. Kaneko S, Ikeda K, Matsuzaki Y, Furuse J, Minami H, Okayama Y, Sunaya T, Ito Y, Inuyama L, Okita K. Safety and effectiveness of sorafenib in Japanese patients with hepatocellular carcinoma in daily medical practice: interim analysis of a prospective postmarketing all-patient surveillance study. $J$ Gastroenterol 2016;51:1011-21.

27. Kudo M, Imanaka K, Chida N, Nakachi K, Tak WY, Takayama T, Yoon JH, Hori T, Kumada H, Hayashi N, Kaneko S, Tsubouchi H, Suh DJ, Furuse J, Okusaka T, Tanaka K, Matsui O, Wada M, Yamaguchi I, Ohya T, Meinhardt G, Okita K. Phase III study of sorafenib after transarterial chemoembolisation in Japanese and Korean patients with unresectable hepatocellular carcinoma. Eur J Cancer 2011;47:2117-27. 